\title{
SÍNDROME MIELODISPLÁSICA POR EXCESSO DE BLASTOS EM CÃo
}

\author{
MYELODYSPLASTIC SYNDROME WITH BLAST EXCESS IN A DOG
}

\author{
P. C. JARK ${ }^{1} *$ F. G. ROMÃ ${ }^{2}$, R. M. VENTURINI-GATTI ${ }^{3}$, F. S. BARROS ${ }^{4}$, C. P. FRACÁCIO ${ }^{4}$, \\ L. H. A. MACHADO ${ }^{5}$, V. E. FABRIS ${ }^{6}$, R. K. TAKAHIRA ${ }^{5}$
}

\section{RESUMO}

As síndromes mielodisplásicas (SMD) são um grupo de desordens adquiridas da medula óssea, caracterizadas por citopenias no sangue periférico, e hipercelularidade na medula óssea com alterações displásicas em uma ou mais linhagens celulares hematopoiéticas. O objetivo do presente relato é descrever um caso de SMD uma vez que esta enfermidade é de ocorrência rara e existem poucos relatos na medicina veterinária.

PALAVRAS-CHAVE: Blastos. Mielodisplasia. Mielograma.

\section{SUMMARY}

The myelodysplastic syndromes (MDS) are a group of bone marrow acquired disorders, characterized by peripheral blood cytopenias, and hypercellular bone marrow with displastyc changes in one or more hematopoietic cell lines. This paper's aim is to report a MDS case since this is a rare disease and there are just a few reports in veterinary medicine.

KEY-WORDS: Blasts. Myelodysplasia. Myelogram.

\footnotetext{
${ }^{1}$ Docente do Departamento de Clínica Médica -Universidade Brasil, campus Descalvado - SP

${ }^{2}$ Docente do Departamento de Clínica Médica - Faculdades Integradas de Ourinhos (FIO)

${ }^{3}$ Médica Veterinária autônoma - Laboratório Labcare, Campinas - SP

${ }^{4}$ Discente do curso de Medicina Veterinária Universidade Brasil, campus Descalvado - SP

${ }^{5}$ Docente do Departamento de Clínica Médica - Unesp - Botucatu, SP

${ }^{6}$ Docente da Faculdade de Medicina - Unesp Botucatu, SP

*Autor para correspondência: paulocjark@hotmail.com
} 


\section{INTRODUÇÃO}

As síndromes mielodisplásicas (SMD) são um grupo heterogêneo de desordens clonais adquiridas da medula óssea descrito em cães, gatos e seres humanos. São caracterizadas por citopenias no sangue periférico e hipercelularidade na medula óssea com alterações displásicas em uma ou mais linhagens celulares hematopoiéticas (WEISS; LULICH, 1999; COUTO, 2006). Pacientes com SMD apresentam risco de progressão para leucemia mielóide aguda (LMA), sendo consideradas por muitos um estado pré-leucêmico (McMANUS, 2005).

As SMD podem ser classificadas em primárias ou secundárias. As primárias são resultado, provavelmente, de alterações genéticas das células-tronco hematopoiéticas, que têm características displásicas e uma taxa acelerada de apoptose (WEISS; AIRD, 2001); já as secundárias estão associadas ao uso de drogas, incluindo agentes quimioterápicos e cefalosporinas (com melhora do quadro após descontinuação do tratamento), linfoma, mielofibrose, trombocitopenia imunomediada, anemia hemolítica imunomediada, mieloma múltiplo e radiação ionizante (WEISS; LULICH, 1999; WEISS, 2003).

O diagnóstico é realizado com base na medicina humana, que é extrapolada para a medicina veterinária. Na presença de 5-29\% de blastos no exame citológico da medula óssea, emprega-se o termo síndrome mielodisplásica por excesso de blastos; se esta porcentagem é maior que 30\%, então o diagnóstico é de leucemia aguda (McMANUS; HESS, 1998; WEISS, 2003). Enquanto a síndrome mielodisplásica é comum em gatos, por causa de infecções por FeLV, esta é uma condição extremamente rara em cães, e pouco se sabe sobre a etiologia, diagnóstico, tratamento e prognóstico (WEISS, 1985; IDE, 2003).

\section{RELATO DE CASO}

Uma cadela, sem raça definida de aproximadamente 11 anos de idade, foi atendida no serviço de Clínica Médica de Pequenos Animais da FMVZ - Universidade Estadual Paulista - "Júlio de Mesquita Filho" - campus de Botucatu, com histórico de hiporexia e apatia de evolução crônica. Segundo o tutor, o animal apresentava este quadro há aproximadamente oito meses.

Ao exame físico, o animal apresentava mucosa ocular discretamente hipocorada e abaulamento abdominal. Os demais parâmetros fisiológicos estavam dentro da normalidade.

Foi solicitado hemograma, que evidenciou trombocitopenia moderada, anemia não-regenerativa e presença de blastos atípicos, com presença de basofilia, vacuolização citoplasmática e nucléolos evidentes. Foi solicitada ultrassonografia abdominal que revelou hepatomegalia e esplenomegalia. Devido à presença de blastos atípicos na circulação periférica, foi solicitado mielograma.

A avaliação citológica da amostra de medula óssea apresentou aumento da celularidade. A série linfóide mostrava-se discretamente hiperplásica com predomínio de pequenos linfócitos e alguns plasmócitos. A relação mielóide:eritróide estava aumentada com presença de $10 \%$ de blastos indiferenciados em uma contagem realizada em 1.000 células (coloração do tipo Romanowsky em aumento de 1.000x) e raras mitoses atípicas (Figura 1). Os blastos apresentaram coloração positiva para Sudan Black o que sugere a origem mielóide. (Figura 2). Os achados do hemograma em conjunto com o mielograma permitiram o diagnóstico de síndrome mielodisplásica por excesso de blastos; porém a classificação em SMD primária e secundária não foi possível devido à grande variedade de distúrbios que podem estar envolvidos na patogênese desta doença.

Foi realizado apenas tratamento de suporte com fluidoterapia, estimulante de apetite, porém o quadro clínico do animal piorou na semana subsequente e o tutor optou pela eutanásia.

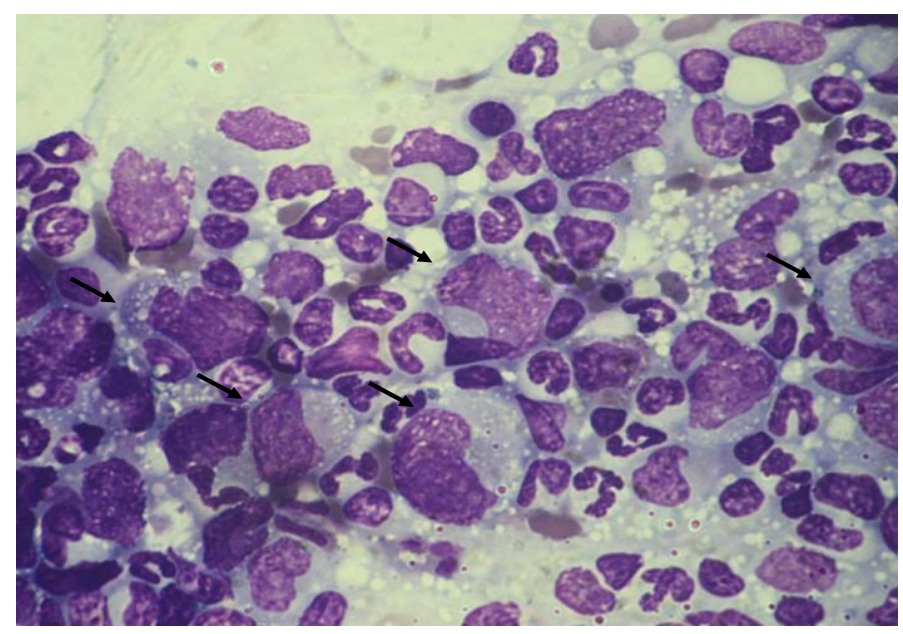

Figura 1 - Presença de blastos indiferenciados (setas) em esfregaço da medula óssea (Coloração do tipo Romanowsky). Aumento de 1.000x (objetiva de imersão) 


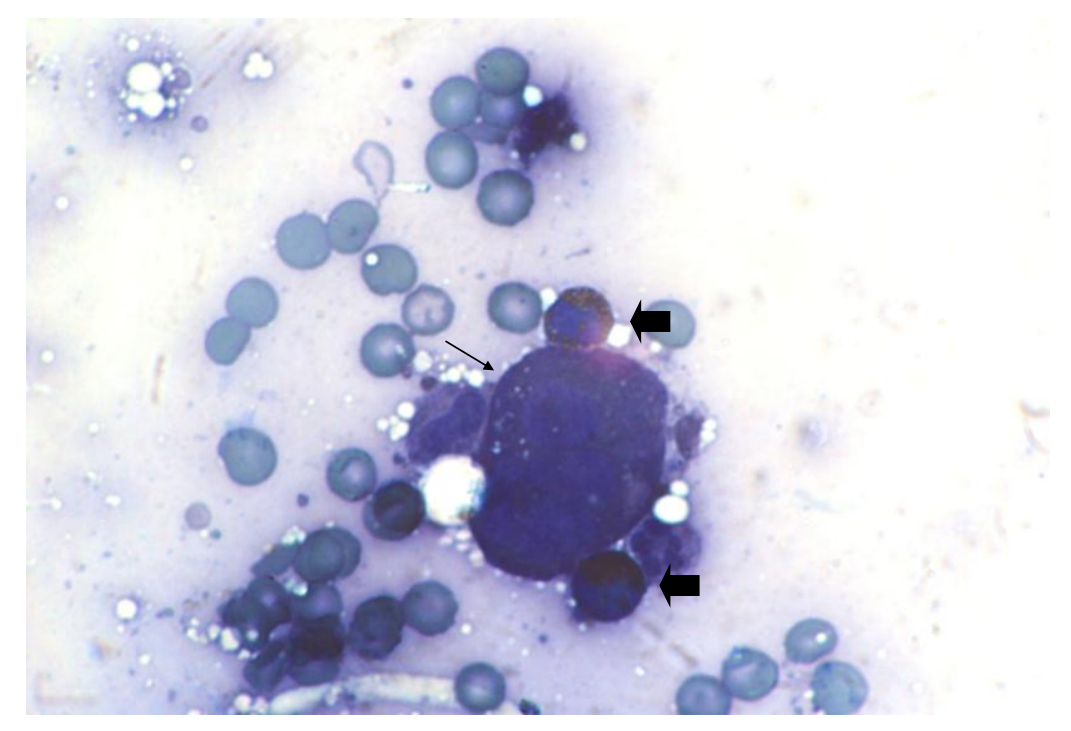

Figura 2 - Blasto apresentando coloração positiva para Sudan Black (seta fina); Duas células de linhagem granulocítica, positivas para Sudan Black (seta grossa). Imprinting de fragmento de medula óssea. Aumento de 1.000x (objetiva de imersão).

\section{DISCUSSAO}

Síndromes mielodisplásicas são caracterizadas pelo número diminuído de células maduras de uma ou mais linhagens celulares no sangue periférico (citopenias) apesar da medula encontrar-se normo ou hipercelular, associada a evidências morfológicas de displasia de formas maduras (diseritropoiese, disgranulopoiese e/ou dismegacariocitopoiese) e uma contagem de 5-29\% de blastos na medula óssea. Este animal apresentava anemia e trombocitopenia e contagem de aproximadamente $10 \%$ de blastos indiferenciados na medula óssea e disgranulopoiese no mielograma.

Algumas causas de mielodisplasia secundária como o linfoma, mielofibroses e policitemia vera podem ser normalmente identificadas através da avaliação clínica e de exames laboratoriais, diagnósticos que foram excluídos no presente relato (WEISS; AIRD, 2001).

Cães que apresentam síndrome mielodisplásica na maioria das vezes são letárgicos, deprimidos e anoréxicos. Os achados do exame físico incluem hepatomegalia, esplenomegalia, palidez de mucosas e febre (COUTO, 2006). O paciente apresentava todas estas características, com exceção da febre.

Causas iniciadoras de síndromes mielodisplásicas ainda não estão bem estabelecidas em cães e os portadores normalmente têm uma sobrevida média de dias a meses após o diagnóstico, variando com o estágio da doença e a gravidade das citopenias. Existe uma grande chance de esta síndrome evoluir para uma leucemia mielóide aguda, sendo nestes casos o prognóstico reservado a desfavorável (McMANUS, 2005).
O tratamento dos cães com SMD ainda é controverso e não foi muito bem estabelecido (IDE, 2003; COUTO, 2006). Uma variedade de novos tratamentos tem sido investigada em humanos, com destaque para a administração de fatores de crescimento hematopoiéticos, drogas que alteram a produção ou bloqueiam os efeitos de algumas citocinas, inibidores da apoptose, agentes citoprotetores, inibidores da metilação do DNA, aminotióis, inibidores da angiogênese, e trióxido arsênico (LIST, 2002). Na medicina veterinária são poucos estudos que avaliaram a eficácia do tratamento, uma vez que é uma doença de ocorrência rara.

\section{CONSIDERAÇÕES FINAIS}

A síndrome mielodisplásica é uma enfermidade de ocorrência rara em cães, o que torna o desenvolvimento de estudos terapêuticos difícil. Em virtude do prognóstico altamente variável, o acompanhamento hematológico dos pacientes acometidos por esta doença é fundamental para a escolha da terapia de suporte, já que tratamentos específicos são pouco descritos na literatura.

\section{REFERÊNCIAS}

COUTO, G. Medicina interna de pequenos animais. Rio de Janeiro: Elsevier, 2006. 1360p.

IDE, K.; MOMOI, Y.; MINEGISHI, M.; SEKIGUCHI, M.; KONNO, K.; IWASAKI, T. A severe hepatic disorder with myelodysplastic syndrome, treated with cytarabine ocfosfate, in a dog. Australian Veterinary Journal, v.81, n.1-2, p.47-49, 2003. 
LIST, A. F. New approaches to the treatment of myelodysplasia. The Oncologist, v.7, n.1, p.39-49, 2002.

McMANUS, P. M.; HESS, R. S. Myelodysplastic changes in a dog with subsequent acute myeloid leukemia. Veterinary Clinical Pathology, v.27, n.4, p.112-115, 1998.

McMANUS, P. M. Classification of Myeloid Neoplasms: a Comparative Review. Veterinary Clinical Pathology, v.34, n.3, p.189-212, 2005.

WEISS, D. J. RASKIN, R.; ZERBE, C. Myelodysplastic syndrome in two dogs. Journal of American Veterinary Medical Association, v.187, n.10, p.1038-1040, 1985.

WEISS, D. J.; LULICH, J. Myelodysplastic syndrome with sideroblastic differentiation in a dog. Veterinary Clinical Pathology, v.28, n.2, p.59-63, 1999.
WEISS, D. J.; AIRD, B. Cytologic evaluation of primary and secondary myelodysplastic syndromes in the dog. Veterinary Clinical Pathology, v.30, n.2, p.67-75, 2001.

WEISS, D. J. New insights into the physiology and treatment of acquired myelodysplastic syndromes and aplastic pancytopenia. Veterinary Clinics of North America: Small Animal Practice, v.33, n.6, p.13171334, 2003. 